\title{
INFLUENCE OF DIGITIZATION INPUT DEVICE ON CALCULATION OF PRINT (NON)UNIFORMITY VALUE OF PRINTS USING ISO 13660 METHOD
}

\author{
Ivana Jurič (D), Dragoljub Novaković (i), Nemanja Kašiković (iD), Sandra Dedijer \\ University of Novi Sad, Faculty of Technical Sciences, \\ Department of Graphic Engineering and Design, Novi Sad, Serbia
}

\begin{abstract}
This paper examines the influence of the digitization input device on the print nonuniformity value when using the ISO 13660 method. This method belongs to the group of techniques called Image Analysis Method (IAM), so the basis for calculating the quality attributes is a digitized print. We selected six different devices: three flatbed scanners and three mobile phones. All settings were constant, such as the scan resolution (600 spi) and light source (D50). To have controlled prints, they were simulated using the MATLAB code - Macro Uniformity Toolbox and printed using the Epson Stylus PRO 7800 InkJet machine. We simulated random print nonuniformity know as small-scaled (graininess) and large-scaled (mottle). The calculated values differ drastically by changing the digitization device, while the values within the same group of devices are strongly correlated. The obtained results indicate the need to expand the standard and define more precise settings for input devices.
\end{abstract}

Keywords: print (non)uniformity, ISO 13660 method, scanner-based system, camera-based system

\section{INTRODUCTION}

There are developed various methods for print quality control, starting from densitometry until spectrophotometry. Recently, one new way has also been introduced for evaluating the print quality of lines, text, print uniformity, registration, etc. It is still underdeveloped but is undoubtedly used for print quality control. The new method is called Image Quality Analysis by some authors (Briggs and Tse, 2005), and it is based on an analysis of the acquired images (i.e., printed samples). We adjusted the name and called it the Image Analysis Method (IAM) because it closely describes the quality control of the prints. Schematic representation of the method is presented in Figure 1. From the original to the numerical values, we need to go through a few steps. The technique can be incorporated into one device (such as QEA Personal IAS or vipFLEX), or the steps could be performed independently.

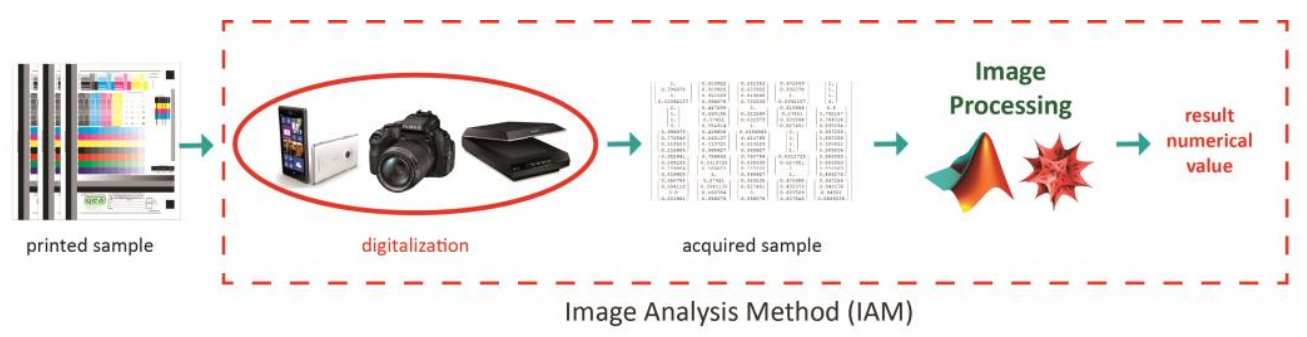

Figure 1: Schematic representation of Image Analysis Method (IAM)

The first international standard that defines procedures and methodology for quantifying essential print quality attributes is ISO 13660:2001 (International Organization for Standardization 13660, 2001; Dhopade, 2009). The standard is device-independent; we can analyze digital, flexo, offset or any other prints (Briggs et al, 1999). According to the standard, the image to be analyzed needs to be digitized using any input device as long as it is capable of sampling the image at a minimum resolution of $600 \mathrm{ppi}$ (International Organization for Standardization 13660, 2001). Responding to the needs of the new standard, instrumentation manufacturers developed a class of devices called image analyzers (Briggs and Tse, 2005). In such a device, the print is acquired with a camera and analyzed (processed) to quantify attributes such as dot gain, line, and text quality, or print nonuniformity such as graininess and mottle. Beside image analyzer, that way of control could be accomplished by using several devices, which together form a system for quality control, called Image Analysis System (Briggs and Tse, 2005). We also adjust this name as Image Analysis Method (IAM). 
Image Analysis System or Image Analysis Method (IAM) includes a light source and some kind of the photodetector in a defined geometric arrangement. In this case, photodetector could be CCD or CMOS sensor. Hence, IAM could be developed in two main styles: the camera-based or flatbed scanner-based system (Briggs and Tse, 2005). Each method has its advantages and disadvantages.

The advantages of the scanner-based system are low cost, and it can easily acquire the entire page area, which can facilitate many print quality analyzes (Briggs and Tse, 2005). The scanner also has built-in illumination, and we can define an area of interest during scanning, that reduces the time of later image processing. On the other hand, this system is time-consuming at high resolutions, and it is a contact method, which leads to the unnaturalness of the scanned sample.

The camera-based system offers higher resolution and very accurate position measurement (Briggs and Tse, 2005). This type of system can be installed directly on the printing machine and provide inline control during printing. It also allows us to upgrade the system by adding other devices such as densitometers and colourimeters. The additional strength of this system is the light source which is away from the sample, so we get a more natural digital sample, as opposed to scanning. The light source is not embedded; therefore, this system is more expensive than the scanner-based one. Also, the camera-based system typically captures only a small section of the printed page at a time, so we need some vacuum table for placing the sample.

Using IAM, we can evaluate print quality according to a large number of attributes. One of the most frequently used attributes is print (non)uniformity (Dhopade, 2009; Lindberg and Fahlcrantz, 2005; Dalal et al, 1998; Petersson, 2005). In the reviewed literature (Petersson, 2005; Christoffersson, 2004; Fahlcratz, 2005; Sadovnikov et al, 2007; Weingerl, 2014; Rasmussen et al, 2006), there are several different definitions of print (non)uniformity. The general physical description would be that the print nonuniformity is an unwanted variation of optical density (reflected light) from the print. Different types of print nonuniformity are presented in Figure 2. Two main groups are random and systematic nonuniformity.
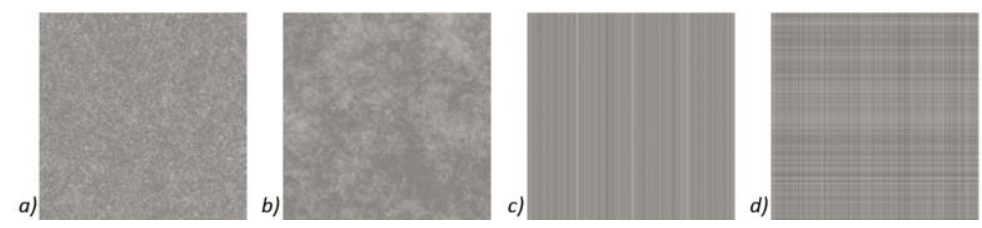

Figure 2: Different types of print nonuniformity: a) small-scale (graininess), b) large-scale (print mottle) random nonuniformity, c) stripes and d) wire mark texture - as systematic nonuniformity (Christoffersson, 2004)

In this paper, we only analyzed random nonuniformity - graininess and print mottle. Print nonuniformity could be quantified using different methods: NU index (Rilovski, 2012), GLCM method (Hladnik and Mihael, 2011; Jurič et al, 2015), standard ISO 13660, method by (Christoffersson, 2004), etc. Common to all methods is that they are based on the IAM method. All methods use the digitized sample for obtaining the numerical value of a print quality attribute which is evaluated. The only difference between them is in the processing of the digitized sample; some of them use the gray level of pixels, some Fast Fourier Transform, etc.

In this paper, we used the method proposed by ISO standard 13660:2001. According to the standard, print mottle is aperiodic fluctuations of density at a spatial frequency less than 0,4 cycles per millimetre in all directions (International Organization for Standardization 13660, 2001). The patch for analyzing print mottle is divided into 100 equal tiles (as shown in Figure 3). Optical density is measured across each tile $i$ several times, and $m_{i}$ is the average of density measurement. The measure of print mottle across the entire patch is the standard deviation of all $m_{i}$ (Weingerl, 2014):

$$
\text { ISO_M }=\sqrt{\frac{1}{n-1} \sum_{i=1}^{n}\left(m_{i}-\left(\frac{1}{n} \sum_{i=1}^{n} m_{i}\right)\right)^{2}}
$$

Where $m_{i}$ is the average density measurement of tile $i, n$ is the total number of tiles.

Graininess is defined as aperiodic fluctuations of density at a spatial frequency greater than 0,4 cycles per millimetre in all directions:

ISO_G $=\sqrt{\frac{\sum_{i=\perp}^{n} \sigma_{i}^{2}}{n}}$ 
where $\sigma_{i}$ is the standard deviation of tile $i, n$ is the total number of tiles.

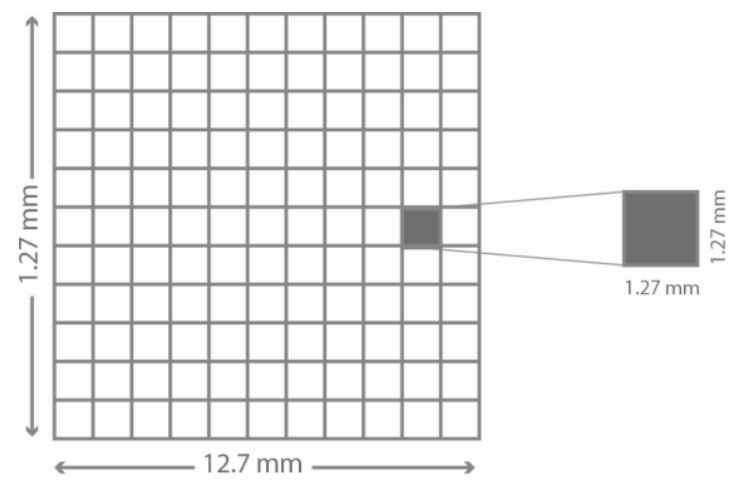

Figure 3: ROI divided into 100 equal parts (tiles), inside which is calculated optical density

The standard ISO 13660:2001 defines the procedures and methodology of various print quality attributes measurement but has its drawbacks. One major drawback of this standard is the lack of reference values. There are no defined acceptance criteria; the user explains it. Once print quality measurements have been made, it is up to those involved to determine if the print quality is acceptable.

In this study, we analyzed the effect of using different devices for digitizing prints on the final value of print quality, measuring graininess and print mottle. As it is shown in Figure 1, we can use the camera, scanner or any other device that has a sufficiently high-quality image sensor, such as a mobile device.

\section{METHODS}

The samples for the experiment were generated using the MATLAB software and plugin Macro Uniformity Toolbook (Rawashdeh, 2006), which is intended to simulate surface nonuniformities in print (Rasmussen et al, 2006). In the mentioned sample generation plugin, it is possible to vary several parameters. For the research, it was chosen to vary the minimum size $\left(p_{\min }\right)$ of the blotch. On all samples, the background color is neutral gray (0.5) (Fahlcrantz, 2005; Lindberg and Fahlcrantz, 2005), and the size of digital samples is $\mathrm{N}=2048 \mathrm{px}$. The parameters for generating all samples are given in Table 1 .

Table 1: Parameters used for generating the samples

\begin{tabular}{|l|l|l|}
\hline Function & Constant parameters & Varied parameter \\
\hline & color $=0.5$ & \\
RN & $p_{\max }=100$ & $p_{\min }=0,0.4,0.6,0.95,2.5,4.5,6.5,9$, \\
(Random Noise) & $\mathrm{A}=0.04$ & $11.5,15.5,21,25.5,29.5,33.5,38,43$, \\
& $\mathrm{N}=2048 \mathrm{px}$ & $48,53.5,58,65,80,94.5$ \\
& Resolution $=300 \mathrm{dpi}$ & \\
\hline
\end{tabular}

Generated samples were printed on IQ Selection whiteboard $\left(250 \mathrm{~g} / \mathrm{m}^{2}\right)$ with inkjet printing machine Epson Stylus PRO 7800. Size of the patch was $160 \times 160 \mathrm{~mm}$ (Jurič, 2018). After print, samples need to be digitized. For this research, we used two different systems: scanner-based and camera-based system. When scanning samples, all automatic corrections were turned off for all devices. Scanning was done in color, 8 bits for each RGB channel. Samples were stored exclusively as TIF format, without compression and without added profile. The standard and previous research papers applying the standard (Briggs et al, 1999; International Organization for Standardization 13660, 2001; Tomić et al, 2016) recommend a scan resolution of 600 spi, which was also used in this paper. Samples were scanned using Adobe Photoshop software and the ScanGear accessory for the Epson Perfection V370 (scanner 1) and CanoScan LIDE 210 (scanner 2) scanners. In contrast, the original manufacturer's software was used for the HP ScanJet 4010 (scanner 3) scanner. The scanners were cleaned with alcohol before use to avoid any unwanted dots from the scanning surface.

Unlike scanning, during digitization of samples with a mobile phone, it is necessary to define the conditions of digitization and device parameters to avoid variations during the experiment. These devices must be positioned and fixed during digitization, so for the purposes of the experiment, it is necessary to 
use the stand. The mobile phone was at a distance of $30 \mathrm{~cm}$ from the sample, and the D50, which simulates daylight, was chosen as the light source. The aperture, shutter speed and ISO value for the mobile phones used in the experiment are listed in Table 2.

Table 2: The aperture, shutter speed and ISO value for the mobile phones used in the experiment

\begin{tabular}{|l|l|l|l|}
\hline Mobile phone & Aperture f & $\begin{array}{l}\text { Shutter } \\
\text { speed [s] }\end{array}$ & ISO \\
\hline $\begin{array}{l}\text { Samsung J5 } \\
\text { (mobile 1) }\end{array}$ & 1.9 & $\begin{array}{l}1 / 50 \\
1 / 100\end{array}$ & $\begin{array}{l}80 \\
125\end{array}$ \\
\hline $\begin{array}{l}\text { Nokia Lumia 630 } \\
\text { (mobile 2) }\end{array}$ & 2.4 & $1 / 35$ & $\begin{array}{l}320 \\
400 \\
500\end{array}$ \\
\hline $\begin{array}{l}\text { iPhone 5 } \\
\text { (mobile 3) }\end{array}$ & 2.4 & $1 / 35$ & 65 \\
\hline
\end{tabular}

After digitization, the samples required necessary processing, which implies only two operations: cutting and rotation. Depending on the resolution of the digitization input device, the fields for later processing are of different dimensions in pixels, and constant dimensions expressed in $\mathrm{cm}$. To avoid blurred edges and the appearance of vignettes, the $16 \times 16 \mathrm{~cm}$ sample was cut to $15.5 \times 15.5 \mathrm{~cm}$. Table 4 shows the field values of $15.5 \times 15.5 \mathrm{~cm}$ expressed in pixels $(\mathrm{px})$ for each device used and each scan resolution.

Table 4: Field size (px) after digitization depending on the input device

\begin{tabular}{|c|c|c|c|c|c|c|}
\hline $\begin{array}{c}\text { Input } \\
\text { device }\end{array}$ & $\begin{array}{c}\text { CanoScan } \\
\text { LIDE 210 }\end{array}$ & $\begin{array}{c}\text { Epson } \\
\text { Perfection } \\
\text { V370 }\end{array}$ & $\begin{array}{c}\text { HP ScanJet } \\
4010\end{array}$ & Samsung J5 & $\begin{array}{c}\text { Nokia } \\
\text { Lumia 630 }\end{array}$ & iPhone 5 \\
\hline $\begin{array}{c}\text { Size of } \\
\text { cropped } \\
\text { patch [px] }\end{array}$ & 3661 & 1700 & 1100 & 1500 \\
\hline Resolution & \multicolumn{3}{|c|}{$600 \mathrm{spi}$} & \multicolumn{3}{|c|}{$72 \mathrm{ppi}$} \\
\hline
\end{tabular}

In Introduction, we mentioned different methods for print (non)uniformity quantification and described the procedure and methodology of ISO 13660 method, which was used in the experiment. For faster calculation, we made MATLAB add-in for quantifying print mottle and graininess based on the methodology described in the standard.

The add-in contained the following steps:

1. import of acquired patch (RGB image),

2. conversation into gray image using built-in Matlab function rgb2gray ( gray $=0.2989 * R+$ $0.5870 * G+0.1140 * B)$,

3. cropping the patch at 100 same tiles,

4. calculation of optical density into one tile (optical density is calculated by the value of the gray level of each pixel) and

5. calculation of print mottle according to standard ISO 13660.

\section{RESULTS AND DISCUSSIONS}

Based on the obtained results of print nonuniformity (Figure 4 and 5), using the ISO method, the samples can be clearly grouped into two sets: micro (graininess) and macro (print mottle) nonuniformity. Regardless of the size of the blotch (spot), some of the samples can be grouped as graininess and some as mottling. The ISO Graininess value increases to sample V4 and then decreases slightly, while the ISO Mottling value slowly rises from the first sample and continues to grow after sample V4. A spot size of $p_{\min }=0.95$ for this sample confirms the definition of the ISO standard 13660, that in mottling the maximum spot frequency is less than $0.4 \mathrm{cy} / \mathrm{mm}$ (ISO, 2001) which corresponds to a spot size $p_{\min }$ of 2.5 taken for sample V5. The maximum frequency for sample V4 is: $f_{\max }=1 / p_{\min }=1.05 \mathrm{cy} / \mathrm{mm}$. Therefore, it can be concluded that samples from V0 to V4 belong to the group of micro nonuniformity. The slope of 
the curve in sample V21, which is most pronounced when using a scanner, confirms that the sample is the same as sample VO - uniform. By enlarging the spot size, a uniform print is obtained again.

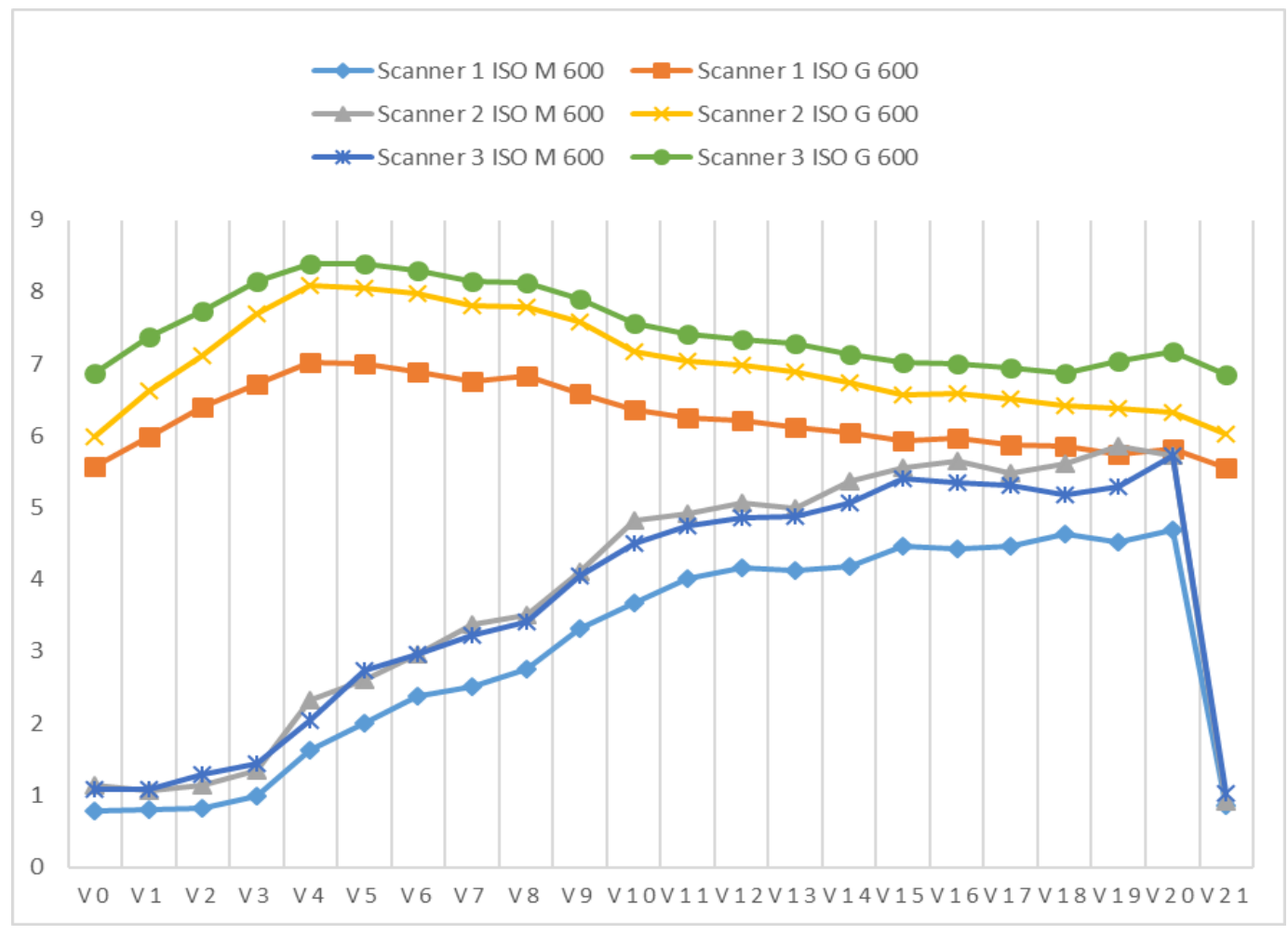

Figure 4: Results of graininess and print mottle using scanners as input device

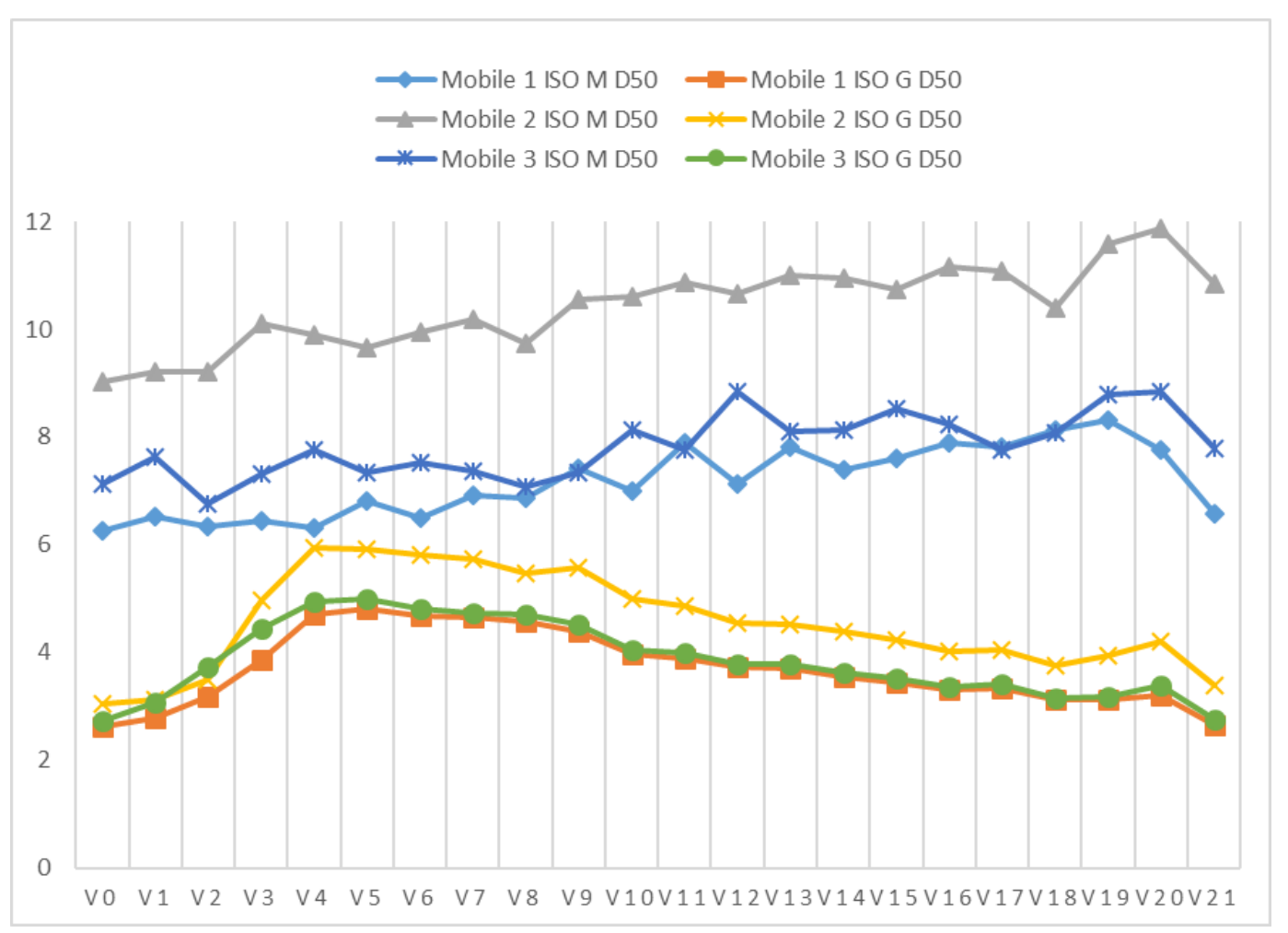

Figure 5: Results of graininess and print mottle using mobile phones as input device 
Based on the graphs, it can be clearly seen that the values obtained using different scanners correlate well, which confirms the value of the correlation coefficient that is above 0.9. However, this is not the same case when looking at mottling values when using mobile phone as input device. The shape of the curve is drastically different, and the correlation is much weaker (0.6 - 0.8). When using a mobile phone, signal noise occurs, which directly affects the calculation of the print mottle, but does not affect the graininess value.

\section{CONCLUSIONS}

Print quality analysis is a crucial part of the printing process and should be conducted in controlled and well-defined conditions. The ISO 13660: 2001 standard has defined new attributes for quality analysis, but is incomplete in terms of methodology. In this paper, the influence of the input device for digitization on the obtained value of print nonuniformity (mottle and graininess) is examined. Based on the results, a clear difference in mottle and graininess values can be seen when different devices are used for digitizing the same samples. The most considerable deviations from the set, initial values appear when measuring mottling when using a mobile phone. The scanner proved to be a more stable and accurate device to use.

\section{ACKNOWLEDGMENTS}

This research (paper) has been supported by the Ministry of Education, Science and Technological Development through the project no. 451-03-68/2020-14/200156: "Innovative scientific and artistic research from the FTS (activity) domain".

\section{REFERENCES}

[1] Briggs, J. C., Forrest, D. J., Klein, A. H., Tse, M. K.: "Living with ISO-13660: Pleasures and perils", International Conference Digital Print Technology, 421-425, 1999. URL:

http://www.qea.com/upload/files/products/Paper_1999\%20IS\%26T-NIP\%20Living\%20with\%20ISO136602.pdf (last request: 2020-10-10).

[2] Briggs, J. C., Tse, M.K.: "Objective Print Quality Analysis and The Portable Personal IAS Image Analysis System", 44, 2005. doi: 10.11370/isj.44.505.

[3] Christoffersson, J.: "Evaluation of Systematic \& Colour Print Mottle", Linkopings Universitet, Sweden, 2004, URL: https://www.diva-portal.org/smash/get/diva2:20130/FULLTEXT01.pdf (last request: 2020-10-10).

[4] Dalal, E. N., Rasmussen, D. R., Nakaya, F., Crean, P. A., Sato, M, Corporation, X.: "Evaluating the Overall Image Quality of Hardcopy Output",169-173, 1998, URL:

https://www.researchgate.net/publication/220865074_Evaluating_the_Overall_Image_Quality_of_ Hardcopy_Output (last request: 2020-10-10).

[5] Dhopade, A.: "Image Quality Assessment According To ISO 13660 and ISO 19751", Test Targe 9, 4350, 2009.

[6] Fahlcrantz, C. M.: "On the evaluation of print mottle", PhD thesis, KTH School of Computer Science and Communication Stockholm, ISBN 91-7178-205-2, 2005.

[7] Hladnik, A., Mihael, L.: "Paper physics: Paper and board surface roughness characterization using laser profilometry and gray level cooccurrence matrix", Nordic Pulp \& Paper Research Journal 26, 99-105, 2011. doi:10.3183/NPPRJ-2011-26-01-p099-105.

[8] International Organization for Standardization, ISO13660 Information Technology - Office Equipment - Measurement of image quality attributes - Binary Monochrome text and graphic images, International Organization for Standardization, 2001.

[9] Jurič, I., Karlović, I., Novaković, D., Tomić, I.: “Comparative study of different methods for the assessment of print mottle", Color Research and Application, 2015. doi:10.1002/col.21984.

[10] Jurič, I.: "Model za kontrolu kvaliteta površinske uniformnosti digitalnih otisaka", PhD thesis, University of Novi Sad, Faculty of Technical Sciences, Department of Graphic Engineering and Design, 2018.

[11] Lindberg, S., Fahlcrantz, C. M.: "Perceptual assessment of simulated print noise with random and periodic structure", Journal of Vision Communication and Image Representation 16, 271-287, 2005. doi:10.1016/j.jvcir.2004.11.002. 
[12] Petersson, J.: "A Review of Perceptual Image Quality", BSc thesis, Department of Science and Technology, Linköpings Universitet, 2005. URL: https://www.divaportal.org/smash/get/diva2:20240/FULLTEXT01.pdf (last request: 2020-10-10).

[13] Rasmussen, D. R., Donohue, K. D., Ng, Y. S., Kress, W. C., Gaykema, F., Zoltner, S.: "ISO 19751 macrouniformity", Proceedings Volume 6059 Image Quality and System Performance III 2006, (SPIE 6059: San Jose, California, 2006). doi:10.1117/12.648086.

[14] Rawashdeh, N.: "Macro Uniformity Toolbox (v2)", URL:

https://www.mathworks.com/matlabcentral/fileexchange/9882-macro-uniformity-toolbox--v2?requestedDomain=true (last request: 2020-10-10).

[15] Rilovski, I.: "Influence of paper surface properties and toner type on digital print mottle", Celuloza Si Hartie 61, 4-9, 2012.

[16] Sadovnikov, A., Lensu, L., Kälviäinen, H.: “Automated Mottling Assessment of Colored Printed Areas", Proceedings of15th Scandinavian Conference 2007, (SCIA:Aalborg, Denmark, 2007), pages 621-630.

[17] Tomić, I., Dedijer, S., Jurič, I., Pál, M.: "The effect of scanning resolution and displacement value on the GLCM-based features for paper texture characterization", Proceedings of the 8th International Symposium on Graphic Engineering and Design 2016, (Department of Graphic Engineering and Design, Faculty of Technical Sciences, University of Novi Sad, 2016), pages, 263-271, URL: http://www.grid.uns.ac.rs/symposium/download/grid16.zip (last request: 2020-10-08).

[18] Weingerl, P.: "Objective methods for print inhomogeneity evaluation and their correlation with visual perception", MSc thesis, Univerza v Ljubljani, 2014.

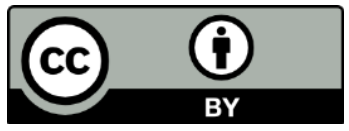

(C) 2020 Authors. Published by the University of Novi Sad, Faculty of Technical Sciences, Department of Graphic Engineering and Design. This article is an open access article distributed under the terms and conditions of the Creative Commons Attribution license 3.0 Serbia (http://creativecommons.org/licenses/by/3.0/rs/). 